\title{
An audit of Paediatric Orofacial Lesions at the Kilimanjaro Christian Medical Centre in Moshi, Tanzania
}

\author{
D. S. Rwakatema ${ }^{1}$, M. L. Chindia ${ }^{2}$ \\ ${ }^{1}$ Kilimanjaro Christian Medical College, Tumaini University, Iringa, Tanzania \\ ${ }^{2}$ School of Dental Sciences, University of Nairobi, Nairobi, Kenya \\ E-mail:rwaka@kcmc.ac.tz,mlchindia@uonbi.ac.ke \\ Received July 20, 2011; revised August 4, 2011; accepted October 17, 2011
}

\begin{abstract}
Objective: To audit and categorize pathological lesions and conditions that occurred in the orofacial region among children aged up to 15 yrs. Setting: Kilimanjaro Christian Medical Centre, Moshi, Tanzania. Design: Retrospective cross-sectional audit based on archival records and material between 1985 to 2005. Results: Biopsy results were generated into 11 categories whence most common lesions encountered were in the categories of soft tissue benign neoplasms (35.1\%) and soft tissue malignant neoplasms (21.8\%). Remarkably, Burkitt's lymphoma (BL) in the category of malignant soft tissue neoplasia constituted $11.8 \%$ of all the lesions biopsied while haemangiomas and tuberculous adenitis comprised $8.1 \%$ and $3.8 \%$ respectively. The age groups revealed the highest burden (37.1\%) among the 0 to 5 -year-olds followed by the 11 to $15-(34.5 \%)$ and 6 to 10 -year-olds $(28.4 \%)$. The orofacial site distribution among the 211 biopsied cases included $62.1 \%$ in the mandibular $29.9 \%$ in the maxillary region and $8 \%$ in the tongue areas. Malignant neoplasms of the bone were rare and all were diagnosed in the mandible. Overall, malignant neoplasms of soft tissue were significantly more in the age group of $6-10$ years as well as in males than females. On the other hand, significantly more benign soft tissue neoplasms occurred in females than in males. Main Outcome Measure: There is great diversity and preponderance of soft tissue than skeletal orofacial lesions on the present audit. Significantly, clinicians should maintain high index of suspicion regarding the remarkably high frequency of diagnosing BL and tuberculous lymphadenitis in such a population in this era of HIV infection/AIDS.
\end{abstract}

Keywords: Orofacial, Neoplasm, Soft Tissue, Tuberculous Lymphadenitis, Lesion, Children, Burkitt Lymphoma, Cross-Sectional Study, Tanzania

\section{Introduction}

Over the past two decades there has been a clear desire, worldwide, for the development of realistic evidencebased oral health policies that are integrated in general health care systems. For this reason, the development of reporting comparable data on oral diseases is essential [1]. Notably, prevailing paradigms in health care prioritization maintain that oral health has a significant impact on nutrition and the overall quality of life [2]. In developing nations such as Tanzania, resources for the provision of adequate oral health care have remained somewhat strained due to limitations in general economic development. It is, therefore, only pertinent that the distribution and optimal utilization of resources in any region in such a diverse nation is based on meticulous docu- mentation of diseases and conditions that may be prevalent regionally.

Regular laboratory audits of the diverse lesions encountered during routine clinical practice could be the tangible measure of the burden and pattern of diseases and conditions that may afflict a specific regional population. Few studies worldwide have attempted to map comprehensive paediatric oral neoplasms [3-7]. Studies of such audits in Tanzania have only been based at the Muhimbili National Hospital [8]. In this investigation, therefore, an analysis was performed of all the archival histopathological reports for orofacial lesions that occurred and had been diagnosed and documented over a 10 -year period at the Kilimanjaro Christian Medical Centre (K.C.M.C.) in Moshi, Northern Tanzania. 


\section{Material and Method}

\subsection{Study Site}

Kilimanjaro Christian Medical Centre is one of the four zonal referral hospitals in Tanzania with a major healthcare facility that serves the vast northern region of Tanzania with regard to histopathology analytical services.

\subsection{Method}

Histology reports that were registered over the period 1985 to 2005 inclusive were analyzed to categorize the variety of oral lesions that were diagnosed. Ethical clearance was sought from Tumaini University, K.C.M.C. Ethics Committee. Data extracted included the age of patients at initial presentation, lesion site, gender, health centre where biopsy was done and the histopathological diagnosis. The case definition for this study was any oral lesion that was diagnosed in the laboratory. Previously diagnosed cases were excluded. No strict attempt was made to categorize the registered lesions according to the International Classification of Diseases. Parameters of interest were analyzed with the Statistical Package for Social Sciences (SPSS) version 12.1 and Epidemiology Information Package (Epilnfo) Chi-square test and Fisher's exact tests were used to evaluate any significant differences on the occurrence of paediatric orofacial lesions. A p-value $<0.05$ was considered significant.

\section{Results}

Processed biopsy results were generated into 11 categories including congenital anomalies, malignant neoplasia of bone, malignant neoplasia of soft tissue, benign neoplasia of soft tissue and dysplastic lesions of bone. Others were benign neoplasia of bone, cystic lesions of bone, cystic lesion of soft tissues, infective lesions of viral origin, bacteria infective lesions and non-specific lesions. The distribution of lesion categories according to age groups revealed the highest burden (36.5\%) among the 0 to 5 -year-olds followed by the 11 to $15-(33.6 \%)$ and 6 to 10 -year-olds (29.9\%). Significantly more children in the age group of $6-10$ and 11 - 15 years were more afflicted in the categories of malignant neoplasia of bone and soft tissue and benign neoplasia of bone than in the age group of 0 - 5-years. Table 1 summarizes the categories of lesions and anomalies diagnosed according to the age groups of children. The site distribution among the 211 biopsied cases included $62.1 \%$ in the mandibular, $29.9 \%$ in the maxillary areas and $8 \%$ in the tongue. All malignant neoplasms of bone diagnosed were osteosarcoma and were all located in the mandible. Table 2 summarizes the categories of lesions and anomalies diagnosed according to the sites biopsied. The most common lesions encountered were soft tissue benign neoplasms (35.1\%) and soft tissue malignant neoplasms (21.8\%). Remarkably, Burkitt's lymphoma (BL) in the category of malignant soft tissue neoplasia constituted $11.8 \%$ of all the lesions biopsied while haemangiomas comprised $8.1 \%$ of the cases. On the other hand the most frequently diagnosed lesion of bacterial origin was tuberculous lymphadenitis $(3.8 \%)$. Significantly more males than females were afflicted by malignant neoplasia of the soft tissue. On the other hand, significantly more benign soft tissue neoplasms occurred in females than males. Table 3 summarizes the categories of lesions and anomalies diagnosed according to gender.

Table 1. A summary of the occurrence of categories of lesions and anomalies diagnosed by biopsy among 211 children according to age groups at K.C.M.C. in the period of 1985-2005.

\begin{tabular}{|c|c|c|c|c|c|}
\hline \multirow{3}{*}{ Diagnosed lesions } & \multicolumn{4}{|c|}{ Age group in years } & \multirow[b]{3}{*}{$\mathrm{p}$-Value } \\
\hline & Total & $0-5(n=77)$ & $6-10(n=63)$ & $11-15(\mathrm{n}=71)$ & \\
\hline & No $(5 \%)$ & No $(\%)$ & No $(\%)$ & No $(\%)$ & \\
\hline Congenital anomalies & $5(2.4)$ & $2(2.6)$ & $3(4.8)$ & $0(0)$ & 0.19 \\
\hline Malignant neoplasia of bone & $2(0.9)$ & $0(0.0)$ & $0(0.0)$ & $2(2.8)$ & 0.00 \\
\hline Malignant neoplasia of soft tissue & $46(21.8)$ & $19(24.7)$ & $19(30.2)$ & $8(11.3)$ & 0.02 \\
\hline Benign neoplasia of bone & $15(7.1)$ & $2(2.6)$ & $3(4.8)$ & $10(14.1)$ & 0.02 \\
\hline Benign neoplasia of soft tissue & $74(35.1)$ & $28(36.4)$ & $20(31.7)$ & $26(36.6)$ & 0.80 \\
\hline Dysplastic lesions of bone & $3(1.4)$ & $0(0.0)$ & $1(1.6)$ & $2(2.8)$ & 0.35 \\
\hline Cystic lesions of bone & $5(2.4)$ & $0(0.0)$ & $1(1.6)$ & $4(5.6)$ & 0.07 \\
\hline Cystic lesions of soft tissues & $12(5.7)$ & $7(9.1)$ & $3(4.8)$ & $2(2.8)$ & 0.24 \\
\hline Infective lesions of viral origin & $2(0.9)$ & $0(0.0)$ & $1(1.6)$ & $1(1.4)$ & 0.57 \\
\hline Bacterial infective lesions & $9(4.3)$ & $2(2.6)$ & $3(4.8)$ & $4(5.6)$ & 0.64 \\
\hline Non specific lesions & $38(18.0)$ & $17(22.1)$ & $9(14.3)$ & $12(16.9)$ & 0.47 \\
\hline
\end{tabular}


Table 2. A summary of the occurrence of categories of lesions and anomalies diagnosed by biopsy among 211 children according to the sites biopsied at K.C.M.C. in the period of 1985-2005.

\begin{tabular}{|c|c|c|c|c|c|}
\hline \multirow[t]{4}{*}{ Diagnosed lesions } & \multirow{4}{*}{$\begin{array}{c}\text { Total } \\
\text { No (\%) }\end{array}$} & \multicolumn{3}{|c|}{ Sites biopsied } & \multirow[b]{4}{*}{ P-value } \\
\hline & & \multirow{3}{*}{$\begin{array}{l}\text { Maxillary areas } \\
\qquad \begin{array}{c}(\mathrm{n}=63) \\
\text { No }(\%)\end{array}\end{array}$} & \multirow{3}{*}{$\begin{array}{l}\text { Mandibular areas } \\
\qquad \begin{array}{c}(\mathrm{n}=131) \\
\text { No }(\%)\end{array}\end{array}$} & \multirow{3}{*}{$\begin{array}{l}\text { Tongue } \\
(\mathrm{n}=17) \\
\text { No }(\%)\end{array}$} & \\
\hline & & & & & \\
\hline & & & & & \\
\hline Congenital anomalies & $5(2.4)$ & $1(1.6)$ & $3(2.3)$ & $1(5.9)$ & 0.58 \\
\hline Malignant neoplasia of bone & $2(0.9)$ & $0(0.0)$ & $2(1.5)$ & $0(0.0)$ & 0.00 \\
\hline Malignant neoplasia of soft tissue & $46(21.8)$ & $15(23.8)$ & $28(21.4)$ & $3(17.6)$ & 0.85 \\
\hline Benign neoplasia of bone & $15(7.1)$ & $6(9.5)$ & $9(6.9)$ & $0(0.0)$ & 0.39 \\
\hline Benign neoplasia of soft tissue & $74(35.1)$ & $28(44.4)$ & $37(28.2)$ & $9(52.9)$ & 0.11 \\
\hline Dysplastic lesions of bone & $3(1.4)$ & $2(3.2)$ & $1(0.8)$ & $0(0.0)$ & 0.36 \\
\hline Cystic lesions of bone & $5(2.4)$ & $2(3.2)$ & $3(2.3)$ & $0(0.0)$ & 0.74 \\
\hline Cystic lesions of soft tissues & $12(5.7)$ & $23.2)$ & $9(6.9)$ & $1(5.9)$ & 0.58 \\
\hline Infective lesions of viral origin & $2(0.9)$ & $0(0.0)$ & $2(1.5)$ & $0(0.0)$ & 0.54 \\
\hline Bacterial infective lesions & $9(4.3)$ & $1(0.6)$ & $8(6.1)$ & $0(0.0)$ & 0.23 \\
\hline Non specific lesions & $38(18.0)$ & $6(9.5)$ & $29(22.1)$ & $3(17.6)$ & 0.10 \\
\hline
\end{tabular}

Table 3. A summary of the occurrence of categories of lesions and anomalies diagnosed by biopsy among 211 children according to gender at K.C.M.C. in the period of 1985-2005.

\begin{tabular}{|c|c|c|c|c|}
\hline \multicolumn{2}{|l|}{ Diagnosed lesions } & \multicolumn{2}{|c|}{ Gender of patient } & \multirow[b]{4}{*}{ P-value } \\
\hline & & Male & Female & \\
\hline & Total & $(\mathrm{n}=110)$ & $(\mathrm{n}=101)$ & \\
\hline & No (\%) & No $(\%)$ & No $(\%)$ & \\
\hline Congenital anomalies & $5(2.4)$ & $3(2.7)$ & $2(2.0)$ & 1.00 \\
\hline Malignant neoplasia of bone & $2(0.9)$ & $1(0.9)$ & $1(1.0)$ & 1.00 \\
\hline Malignant neoplasia of soft tissue & $46(21.8)$ & $30(27.3)$ & $16(15.8)$ & 0.05 \\
\hline Benign neoplasia of bone & $15(7.1)$ & $8(7.3)$ & $7(6.9)$ & 0.86 \\
\hline Benign neoplasia of soft tissue & $74(35.1)$ & $29(26.4)$ & $45(44.6)$ & 0.01 \\
\hline Dysplastic lesions of bone & $3(1.4)$ & $1(0.9)$ & $2(2.0)$ & 0.61 \\
\hline Cystic lesions of bone & $5(2.4)$ & $3(2.7)$ & $2(2.0)$ & 1.00 \\
\hline Cystic lesions of soft tissues & $12(5.7)$ & $6(5.5)$ & $6(5.9)$ & 0.88 \\
\hline Infective lesions of viral origin & $2(0.9)$ & $1(0.9)$ & $1(1.0)$ & 1.00 \\
\hline Bacterial infective lesions & $9(4.3)$ & $5(4.5)$ & $4(4.0)$ & 1.00 \\
\hline Non specific lesions & $38(18.0)$ & $23(20.9)$ & $15(14.9)$ & 0.33 \\
\hline
\end{tabular}

\section{Discussions}

The regional population health profiles in a country such as Tanzania have to be, largely, heterogeneous across the expansive provinces. Knowledge of the pattern and burden of diseases and conditions that may be prevalent among regional populations should constitute the logical benchmark upon which healthcare delivery could be more efficiently implemented. While the most reliable measures of any relevant healthcare needs may best be achieved through population-based surveys, they are often resource-intensive and would require prolonged pe- riods to collate. On the other hand laboratory-based audits at major regional health facilities should offer tangible information, albeit restrictive, on the pattern of and gravity of diseases and conditions that may be prevalent across the region. In the present investigation, the occurrence of BL was relatively low compared to the one reported in Dar-Es Salaam among Tanzanian children [8]. Probably this may be consistent with what has been stated in other studies that most biopsies in some centres with regard to BL may relate to geographical clinical presentation thus affecting clinicians to decisions biopsy [9, $10]$. It is worthy of note, in this study, that about $21.8 \%$ 
of the diagnosed lesions were malignant neoplasms of the soft tissues which was half the number of malignant neoplasm findings at Muhimbili National Hospital in Tanzanian children of a similar age group [8]. Since BL was categorized into malignant neoplasm of the soft tissues its occurrence took a larger portion in this category. The same trend was also observed in other studies in this region $[6,8,11]$. In healthcare, the desirable resources to optimally manage malignant diseases can be elaborate and expensive. The present findings should, therefore, provide useful guidelines for health planners and managers as to how to logically and proportionately utilize available resources.

With the present findings and others available elsewhere in the region $[1,8]$, sufficient information should evolve to facilitate the possibilities of mapping out the pattern and gravity of diseases and conditions that may be prevalent in children across the East African region. This may give the region the capacity of comparing information regarding these lesions with other countries worldwide. For instance the present investigation has highlighted the dissimilarities of the occurrence of malignant neoplasms as compared to a similar report in South American children [3].

In addition to, the essence of highlighting the pattern and burden of malignant disease in a population cohort such as the present one, it is also important to note the significant burden of benign neoplasms. Early in life benign neoplasms if not timely diagnosed and treated, are often most debilitating and difficult to manage. In the present investigation, as in several other studies $[4,7,12]$ the haemangioma was the most commonly diagnosed neoplasm. This lesion and pleomorphic adenoma depending on their location and extent, pose significant challenges in terms of definitive management not only in the professional context but also the man-hours and school-hours that may be lost while seeking treatment for these minors. The occurrence of $3.8 \%$ of cases of tuberculous lymphadenitis in this study was quite alarming and probably was an indicator of the HIV infection/ AIDS burden in this population [13].

Although they occurred rarely, malignant and benign neoplasms of bone were significantly higher at the age group of $11-15$ years than at the other two age groups. This is the age of accelerated growth especially in the bone. Higher chances of bone neoplastic changes are likely to occur in this period of growth. Overall, the present investigation has yielded useful baseline information that is certainly most pertinent for those in clinical practice who must maintain logical indices of diagnosing diverse lesions in the orofacial region. In the absence of analytical population-based studies, laboratory-based audits shall remain relevant and should be encouraged.

\section{Conclusions}

Evidently, there is a considerable diversity and preponderance of soft tissue than skeletal oral lesions based on the present audit. Remarkably, clinicians should maintain a high index of suspicion regarding the high frequency of diagnosing $\mathrm{BL}$ in such a population.

\section{Acknowledgements}

The authors are grateful to the authorities of Kilimanjaro Christian Medical Centre Histopathology Department for allowing retrieval of biopsy reports of this study. The authors appreciate the help from Miss Sally Musinde of the Department of Oral and Maxillofacial Surgery, School of Dental Sciences, University of Nairobi, Kenya for her involvement in the preparation of the manuscript.

\section{References}

[1] E. A. O. Dimba, J. Gichana, A. A. K. Limo, K. A. Wakoli, M. L. Chindia and D. O. Awange, "An Audit of Oral Disease at a Nairobi Centre, 2000-2004," International Dental Journal, Vol. 57, No. 6, 2007, pp. 439-444.

[2] P. E. Pertersen, "The World Oral Health Report 2003 Continuous Improvement of Oral Health in the $21^{\text {st }}$ Century the Approach of the WHO Oral Health Global Programme." Community Dental Oral Epidemiology, Vol. 31, No. 1, 2003, pp. 3-24. doi:10.1046/j..2003.com122.x

[3] G. S. Lima, et al, "A Survey of Oral and Maxillofacial Biopsies in Children: A Single-Centre Retrospective Study of 20 Years in Pelotas-Brazil," Journal of Applied Oral Science, Vol. 16, No. 6, pp. 397-402. doi:10.1590/S1678-77572008000600008

[4] M. Sato, N. Tanaka, T. Sato and T. Amagasa. "Oral and Maxillofacial Tumours in Children: A Review," British Journal of Oral \& Maxillofacial Surgery, Vol. 35, No. 2, 1997, pp. 92-95. doi:10.1016/S0266-4356(97)90682-3

[5] Y. Wang, H. Chang, J. Y. Chang, G. Hung and M. Guo, "Retrospective Survey of Biopsied Oral Lesions in Pediatric Patients," Journal of Formos Medical Association, Vol. 108, No. 11, 2008, pp. 862-871. doi:10.1016/S0929-6646(09)60418-6

[6] S. B. Aregbesola, V. I. Ugboko, J. A. Akinwande, G. F. Arole and O. O. Faga, "Orofacial Tumours in Suburban Nigerian Children and Adolescents," British Journal of Oral and Maxillofacial Surgery, Vo. 43, No. 3, 2005, pp. 226-231. doi:10.1016/j.bjoms.2004.11.006

[7] T. A-Khateeb, A. A Hamasha and N. M. Almasri, "Oral and Maxillofacial tumours in North Jordanian Children and Adolescents: A Retrospective Analysis over 10 Yeras," International Journal of Oral and Maxillofacial Surgery, Vol. 32, No. 1, 2003, pp. 78-83. doi:10.1054/ijom.2002.0309

[8] B. M. Kalyanyama, M. I. N. Matee and E. Vahahula, "Oral Tumours in Tanzanian Children Based on Biopsy 
Materials Examined over a 15-Year Period from 1982 to 1997," International Dental Journal, Vol. 52, No. 1, 2002, pp. 10-14. doi:10.1111/j.1875-595X.2002.tb00590.x

[9] W. O. Mwanda, J. Orem, S. C. Remick, R. Rochford, C. Whalen and M. L. Wilson, "Clinical Characteristics of Burkitt's Lymphoma from Three Regions in Kenya," East African Medical Journal, Vol. 82, No. 9, 2005, pp. S135-143

[10] A. Kamulegeye and B. Kalyanyama, "Oral Maxillofacial Neoplasms in an East African Population a 10 Year Retrospective Study of 1863 Cases Using Histopathological Reports," 2008.

http://www.biomedcentral.com/1472-6831/8/19
[11] J. M. Wakiaga, J. F. Onyango and D. O. Awange, "Clinicopathological Analysis of Jaw Tumours and Tumour-Like Conditions at the Kenyanta National Hospital," East African Medical Journal, Vol. 74, No. 2, 1997, pp. 65-68.

[12] N. Tanaka, A. Murata, A. Yamaguchi and G. Kohama, "Clinical Features and Management of Oral and Maxillofacial Tumours in Children," Oral Surgery, Oral Medicine, Oral Pathology, Oral Radiology and Endodontology, Vol. 88, No. 1, 1999, pp. 11-15.

[13] WHO, "Global Tuberculosis Control-Epidemiology, Strategy, Financing,” WHO Report, Geneva, 2009. 